\title{
Public trust: caught between hype and need
}

\author{
Felix Gille ${ }^{1}$ (1) $\cdot$ Caroline Brall ${ }^{1}$
}

Received: 5 February 2020 / Revised: 12 February 2020 / Accepted: 18 February 2020 / Published online: 29 February 2020

(C) Swiss School of Public Health (SSPH+) 2020

Public trust is indispensable for the well-functioning of health system activities (Gille et al. 2017). We understand public trust to be a concept that grows in the public sphere from open public discourse and as a result legitimises the actions of health systems. Public trust builds on information equally relating to past experiences, present perceptions and future expectations. Public trust is established in anticipation of a net benefit for the public as well as the system (Gille et al. 2020).

Public trust is, for instance, crucial for the success or failure of setting up national health databases (van Staa et al. 2016). The National Health Service England initiative care.data that aimed to link individual care data to improve quality of care for all failed before launch due to lacking public trust to keep personal data secure and protect personal data from corporate exploitation. Also, on a macrolevel, acceptance of priority setting in health policy depends on public trust (Brall et al. 2019). Here, lack of trust is described as being a major failure for effective health policy-making. Policy-makers who act according to values that are in line with public values are more trusted than others. Last, high public vaccination coverage is associated with public trust in health authorities and the wider government. Simplified, where levels of public trust are low, vaccine coverage is usually lower as well (Ozawa and Stack 2013).

At present, we witness that the concept of trust literally appears everywhere in the public sphere. Frevert described this with the word obsession in 2013 and the 2019 Ipsos Mori report on trust also mentions this obsession (Frevert 2013; Ipsos Mori 2019). Yet, we argue that the present

This Editorial is published to mark the 15th anniversary of the Swiss School of Public Health.

Felix Gille

felix.gille@hest.ethz.ch

1 Department of Health Sciences and Technology, Health Ethics and Policy Lab, ETH Zurich, Hottingerstrasse 10, 8092 Zurich, Switzerland visibility of the concept trust in the public sphere goes beyond obsession and is converted for other purposes: trust became a Buzz-Word. Trust is extremely hyped and degenerated to a marketing term where we see that not only international companies advertise with trust, but also insurance companies, or even hand cream products have the word trust printed on their tube. We argue, this inflationary and at times absurd use does diminish the true value of trust as it wears trust out. Likely one of the most striking problems regarding the overuse of trust and how the term is marketed is a conceptual misunderstanding. Why should we trust a person or company that says 'Trust me'? This is conceptually problematic as trust cannot be enforced upon others. Rather, the trustworthiness of the to-be-trusted will always be assessed by the trusting party (Hartmann 1994). Likely, such marketing use of the term 'trust' will lead to the opposite as intended-less or no trust-because the tobe-trusted repels the target groups.

At the same time, we suspect that the appearance of the term trust in public discourse is indeed an indicator for the public need to address problems of trust in relation to health systems. Studies from within and outside of health systems since years make references to decreasing levels of trust or even refer to a 'trust crisis' (Abelson et al. 2009). In contrast and complicating the trust discourse, current polls show in fact high levels of trust in health professionals. For example, in the UK health professionals are the most trusted profession where $96 \%$ of participants trust nurses and $92 \%$ of participants trust doctors to tell the truth. Those high numbers are stable over the last years (Ipsos Mori 2019). The overall perception of decreasing levels of public trust in the entire health system might be explained by the fact that government officials, insurance companies or the private sector are also health system actors, which are considerably less trusted if not least trusted, as is the case for politicians (Ipsos Mori 2019). These lower levels of public trust which span across health systems are a true problem and might therefore accelerated a hype around trust, as described above, where different actors vie for trust. 
Public trust will not grow by hackneyed overuse of the term trust. We argue firmly that we need to be careful to not eradicate the precious value of trust by hyping and overusing the term. Rather we need evidence informed and reasonable discourse in the public sphere, including all actors across the health system, to discuss issues of trust in a meaningful way. This public discourse needs to be open to the general public. Where health system actors aim to appear trustworthy, they need to convey honest and truthful information. From a public viewpoint, this information needs to be threefold: at first, the public needs to be able to relate to past experiences or comparative experience to achieve a feeling of familiarity. At second, the actor needs to communicate its present capability to fulfil what it ought to be trusted for. Last, the actor needs to describe in a comprehensive way which steps s/he will follow in the future to fulfil what $\mathrm{s} / \mathrm{he}$ is trusted for. Eventually, if the public considers an actor trustworthy and expresses its trust, the actor has a legitimate foundation to act for what $\mathrm{s} / \mathrm{he}$ is trusted for and the public will participate in trusted action. Participation of the trusting party and legitimacy of the trusted party are the conclusive effects of a trusting relationship (Gille et al. 2020). In this meaningful way, trust can and should be established, rather than hyping a Buzz-Word.

Acknowledgement This editorial is based on an evening lecture we gave in spring 2020 in Zurich, Switzerland, on the occasion of the 15th anniversary of the Swiss School of Public Health. We would like to thank the organizers for the opportunity to present our thoughts on public trust in health systems.

\section{Compliance with ethical standards}

Conflict of interest We declare no conflict of interest.

\section{References}

Abelson J, Miller FA, Giacomini M (2009) What does it mean to trust a health system? A qualitative study of Canadian health care values. Health Policy 91(1):63-70. https://doi.org/10.1016/j. healthpol.2008.11.006

Brall C, Schröder-Bäck P, Porz R, Tahzib F, Brand H (2019) Ethics, health policy-making and the economic crisis: a qualitative interview study with European policy-makers. Int J Equity Health 18(1):144. https://doi.org/10.1186/s12939-019-1050-y

Frevert U (2013) Vertrauensfragen: Eine Obsession Der Moderne. Beck, München

Gille F, Smith S, Mays N (2017) Towards a broader conceptualisation of 'public trust' in the health care system. Soc Theory Health 15(1):25-43. https://doi.org/10.1057/s41285-016-0017-y

Gille F, Smith S, Mays N (2020) What is public trust in the healthcare system? A new conceptual framework developed from qualitative data in England. Soc Theory Health. https://doi.org/10.1057/ s41285-020-00129-x

Hartmann M (1994) Die Praxis Des Vertrauens. Suhrkamp, Berlin

Ipsos Mori (2019) Trust: the truth? https://www.ipsos.com/ipsosmori/en-uk/ipsos-thinks-trust-truth. Accessed 12 February 2020

Ozawa S, Stack ML (2013) Public trust and vaccine acceptanceinternational perspectives. Human Vaccin Immunother 9(8):1774-1778. https://doi.org/10.4161/hv.24961

van Staa T-P, Goldacre B, Buchan I, Smeeth L (2016) Big health data: the need to earn public trust. BMJ. https://doi.org/10.1136/ bmj.i3636

Publisher's Note Springer Nature remains neutral with regard to jurisdictional claims in published maps and institutional affiliations. 